ARBOR Ciencia, Pensamiento y Cultura

Vol. 187 - 751 septiembre-octubre (2011) 977-982 ISSN: 0210-1963 doi: 10.3989 /arbor. $2011.751 \mathrm{n} 5013$

\section{ESPAÑA Y LOS ESPAÑOLES}

\author{
Rubén Caba \\ Escritor \\ rc.caba@hotmail.es
}

\begin{abstract}
The author here argues in favour of the historical reality that we call Spain. To recognize the Cadiz Constitution of 1812 as the origin of present Spain, he maintains, does not imply that our country had no national identity before the 19th century. And to this effect he expounds the famous controversy between Americo Castro and Claudio Sánchez-Albornoz. Before the Arab invasion there were no "españoles", since this word of provençal origin dates back to the 11 th century, as Castro points out. However, it is also true that during the Roman as well the Gothic domination, the peninsular inhabitants were known as "hispani", as Sánchez-Albornoz sarcastically alleges. In addition, this article includes a number of quotations from Latin, Gothic and Spanish writers of the Middle Ages and the Renaissance, references which bear witness to a feeling of belonging to an old country called "Hispania" or "España".
\end{abstract}

KEY WORDS: Cadiz Constitution; Spain; spaniards; Hispania; hispani; Arab invasion; Américo Castro; Claudio Sánchez-Albornoz; Alfonso $X$.

Compartir un espacio geográfico y unas experiencias históricas no implica comulgar con ideas y creencias ni adoptar el modo de vida de una comunidad. Uno puede sentirse más cercano a un asiático o a un americano residente en el otro extremo del mundo que a los vecinos de su mismo barrio. Pero nada tienen que ver las afinidades electivas con el empeño en ignorar, moda reciente, que España es una realidad histórica. Justo es reprobar las páginas negras de nuestra historia, parecidas en sordidez a las épocas de expansión y dominio de otras naciones, y abominar de los gobernantes tiránicos que oprimieron a su propio pueblo, tan semejantes a los déspotas de cualquier otro pais. Sin embargo, sorprende que incluso los extranjeros críticos con España tengan una idea más amplia, precisa y nítida de nuestro pais que algunos españoles de hoy.

La moda de tergiversar los datos históricos ha adquirido tanto glamour intelectual que algunos escritores y articulistas sostienen que España como nación data del siglo XIX

\section{SPAIN AND THE SPANIARDS}

RESUMEN: El autor aporta argumentos en favor de la realidad histórica que llamamos España. Sostiene que reconocer a la Constitución de Cádiz de 1812 como origen de la España política actual no implica que nuestro pais careciera de identidad nacional antes del siglo XIX. Y expone la controversia de Américo Castro y de Claudio Sánchez-Albornoz sobre la génesis histórica de España para concluir que, si bien antes de la invasión árabe no habia "españoles", vocablo provenzal del siglo XI como advierte Castro, también es cierto que durante la dominación romana y goda los peninsulares eran "hispani", como alega con sorna Sánchez-Albornoz. Además, se recogen citas de autores latinos, godos y españoles tanto medievales como renacentistas que testimonian su sentimiento de pertenecer a un viejo país Ilamado Hispania o España.

PALABRAS CLAVE: Constitución de Cádiz; España; españoles; Hispania; hispani; invasión árabe; Américo Castro; Claudio SánchezAlbornoz; Alfonso X.

o, como mucho, del XVIII. Para promover sus fines ideológicos, no siempre confesos, distorsionan los hechos del pasado al reflejarlos en los espejos convexos o cóncavos de sus intereses partidistas. Cierto que, al grito de iVive la nation!, las milicias de la Revolución Francesa organizadas por la Convención Nacional vencieron a los realistas en la batalla de Valmy. Pero cuando el movimiento romántico dio en sacralizar la nación, que encarnaba el espíritu del pueblo (Volkgeist), inoculó el virus nacionalista -ostentación patológica de superioridad- en el organismo sano de cualquier pueblo interracial asentado en un territorio a lo largo del tiempo.

En todo caso, la nación concebida como pueblo es una realidad cultural que no debe identificarse con una determinada estructura jurídica del Estado. El hecho de que la España política actual provenga de la Constitución de Cádiz de 1812, no significa que antes del siglo XIX España careciera de identidad nacional, porque la nación 
no es un término unívoco. En su acepción primaria es un sentimiento telúrico que se nutre del humus de la patria. Metáforas emocionales que pertenecen a distintas dimensiones temporales: la nación es el presente y el futuro de un pasado común que se percibe como patria. La nación es designio; la patria, nostalgia. Pero tampoco la patria es unívoca. Adopta acepciones diferentes y aun opuestas: hay patriotas del poder y patriotas del saber; patriotas del dogma y patriotas de la libertad; patriotas aldeanos y patriotas ecuménicos.

El vocablo nación, como concepto unitario aplicado a los habitantes de la Península e islas Baleares, se empleó desde finales de la Edad Media. En la segunda mitad del siglo XV, el corregidor de Toledo don Gómez Manrique, tío del poeta Jorge Manrique, en su Regimiento de Príncipes, libro que dedicó a los Reyes Católicos, llamó "Señor de nuestra nación" a don Rodrigo, el último rey godo que "perdió todas las Españas" (Manrique, 1984, 7. ${ }^{\text {a estrofa). Y }}$ en los primeros años de aquel siglo, Pedro López de Ayala también mencionó en su Rimado de Palacio a catalanes, lombardos y escoceses como naciones de Europa.

Eso explica que algunos políticos de nuestra democracia hayan difundido que Cervantes llamó a España "nación de naciones", expresión que no he encontrado en los textos de Cervantes. Quizá se refieran al pasaje de Los trabajos de Persiles y Sigismunda donde un personaje dice: "Yo... soy extranjero y de nación polaca; muchacho salí de mi tierra y vine a España, como a centro de los extranjeros y a madre común de las naciones" (Cervantes, 1970, III, cap. 6). No está claro que se aluda a naciones peninsulares, sino a otras naciones europeas dominadas entonces por España, como sugiere el personaje al declararse de nación polaca. En cambio, Cervantes sí escribió que Sansón Carrasco se burló de don Quijote llamándolo "honor y espejo de la nación española" (Cervantes, 1998, II, 682).

Ya advirtió Ortega y Gasset que la nación, como proyecto sugestivo de vida colectiva, es el precipitado de un Estado mestizo y plurilingüe que, tras la unificación política, adopta una lengua común. Así que la unidad lingüística es el efecto, no la causa, de la unión política. La Constitución de 1978, fecundada por el espíritu liberal de 1812, declara en su artículo 2 que "se fundamenta en la indisoluble unidad de la Nación española, patria común e indivisible de todos los españoles, y recoge y garantiza el derecho a la autonomía de las nacionalidades y regiones que la integran y la solidaridad entre todas ellas". No es una cláusula ornamental, sino la piedra angular de la convivencia democrática de los ciudadanos.

Sin embargo, en estos últimos años, la vida política en España parece marchar por el carril contrario de las sociedades avanzadas. Según los ideólogos de la España autonómica, somos de hecho un Estado plurinacional, mientras que Estados Unidos, Canadá, México, Argentina, Brasil, Alemania y muchos otros países se han estructurado como una Nación pluriestatal, lo que les ha permitido descentralizar los órganos de poder sin menoscabar la unidad básica de una sociedad plural. El debate sobre la nación remite a la cuestión de qué entendemos por España y los españoles. Y mientras que la nación es un impulso y la patria una evocación, España es además una noción histórica y una concreción geográfica.

Incluso José Álvarez Junco, cuyo ensayo histórico Mater Dolorosa, editado a principios de este siglo, ha suscitado no pocas interpretaciones torticeras, reconoce que las fronteras de la estructura política Ilamada España "se han mantenido básicamente estables a lo largo de los últimos quinientos años, fenómeno digno de estudio y aun extraordinario si se tiene en cuenta la enorme fluidez fronteriza del continente europeo durante ese período. Por muchos que hayan podido ser sus problemas en el siglo $\mathrm{XX}$, la española ha sido la identidad política de mayor éxito de las surgidas en la península Ibérica durante, digamos, el último milenio" (Álvarez Junco, 2001, 20).

En el siglo pasado, Claudio Sánchez-Albornoz estudió en su España, un enigma histórico las raíces de la génesis histórica de España, brotadas mucho siglos antes que la marea islámica alcanzara las tierras peninsulares, hito cronológico que Américo Castro había propuesto en España en su historia, reeditado con el título La realidad histórica de España.

En un ensayo posterior, Los españoles: cómo llegaron a serlo, Castro advirtió que bajo el Imperio Romano y durante la dominación de los godos, los peninsulares aún eran hispani. Sorprendente conclusión que cualquiera suscribiría nada más saber que el gentilicio "español", registrado desde fines del siglo XI y de origen provenzal, designaba a los habitantes de los reinos cristianos de la Península. 
En otro ensayo editado cinco años después, "Español", palabra extranjera: razones y motivos, Castro sostuvo en el capítulo "Cómo comenzó a haber españoles" que la traducción del vocablo latino hispani por españoles en la Primera Crónica General, compilada por orden de Alfonso X a fines del siglo XIII, tuvo "desastrosas consecuencias para la historiografía española", porque "ambas palabras fueron dotadas de la misma dimensión espacio-temporal" (Castro, $1973,79)$. Sinonimia que se oponía a su tesis de que antes del siglo VIII no había españoles en la Península.

Estos dos ensayos de Américo Castro se reeditaron juntos en Taurus con el título Sobre el nombre y el quién de los españoles. Más ceñido a la realidad hubiera sido aunarlos bajo el rótulo Cómo los hispani pasaron a llamarse españoles. Sin embargo, empeñado en que los hechos del ayer rimaran con sus afecciones e ideas personales, la ambición ontológica le exigió ocuparse de cómo empezó a haber españoles o de cómo llegaron a serlo a raíz de la invasión islámica que, según él, actuó como partera, aunque la criatura ya llevaba muchos siglos en el mundo.

Tantos llevaba que su idioma, el latín corrupto o romance, lo hablaban todos en Al-Ándalus, incluso el califa Abderramán III y los nobles de estirpe oriental que eran bilingües, como anotó Sánchez-Albornoz en su España, un enigma histórico. Y en el mismo pasaje, Sánchez-Albornoz cita al arabista Emilio García Gómez: "Hoy empezamos a entrever con claridad la importancia que tenía el bilingüismo en la España musulmana y la esfera reducida a que dentro del país se hallaba confinado el árabe puro" (Sánchez-Albornoz, 1956, I, 143).

No es de extrañar que, además de Sánchez-Albornoz, refutaran las tesis de Castro un buen número de eruditos desde posiciones historiográficas diversas y aun opuestas entre sí. Castro las rechazó con expresiones dictadas por su ancestral temperamento español que, mal que le pese, había heredado de los hispanos, de los iberos y demás integrantes de la población interracial de la Península e islas Baleares. En "Peculiaridad del tema español", páginas publicadas entre los "Últimos escritos" incluidos en Sobre el nombre y el quién de los españoles, se quejó de que su "nueva visión del pasado español ha sido acogido con reacciones más propias de jauría de canes o de manada de lobos que de seres humanos" (Castro, 1973, 401). Improperios que traen a la memoria la disputa teológica que, en el siglo VIII, mantuvieron el Beato de Liébana y el arzobispo Elipando de Toledo. Acabó como el rosario de la aurora: el monje llamó testículo del Anticristo al prelado, y éste al monje, borracho y farsante. Así se las gastaban ya los piadosos hispani.

Es de suponer que entre los canes y lobos no incluya al autor de La formación de los dominios lingüísticos en la Península ibérica, puesto que es obra de un sabio lingüista alemán, así calificado por Castro en la "Nota final" de Los españoles: cómo llegaron a serlo. Su autor sostiene, según el propio Castro, que "la reaparición en los siglos medievales de las viejas características temperamentales de los españoles anteriores a Cristo... permite conjeturar que la acción del señorío romano sobre la personalidad arriscada y vehemente de los peninsulares no debió ser sino un sedante pasajero que no logró cambiar esencialmente el carácter y el destino de los hispanos" (Ibídem, 371). Ante refutación tan contundente de sus tesis, Castro sólo acierta a balbucear que "el señor [Kurt] Baldinger no dice de dónde salieron los españoles anteriores a Cristo" (Ídem). La objeción se las trae, por decirlo suavemente.

En todo caso, el agua hispana que sigue moviendo los molinos peninsulares viene de muy lejos. La realidad geográfica e histórica llamada España arranca de la dominación romana, cuyos historiadores y escritores de otras partes del Imperio llamaban hispanus al habitante o al oriundo de Hispania, topónimo de origen fenicio. La misma península que los griegos Ilamaron Iberia por el río Íber, hoy Ebro. Quien desee conocer el gran número de topónimos y gentilicios griegos de lberia que han Ilegado hasta nuestros días, no tiene más que leer el libro III de la Geografía escrita por Estrabón en el siglo I anterior a nuestra era.

En cuanto a hispano, la primera mención aparece en un fragmento del latino Ennius, quien hacia el año 200 antes de J.C. escribió: "Hispane, non Romane memoretis loqui me". Antonio García y Bellido, que aporta en sus Veinticinco estampas de la España antigua esta cita, la traduce así: "Acordaos de que me habéis oído hablar como hispano, no como romano" (Garcia y Bellido, 1977, 214). Y conjetura que quizá se trate de un embajador hispano en Roma. García y Bellido señala que esta mención del vocablo etnicogeográfico implica que ya se empleaba el nombre de Hispania. Por su parte, Sánchez-Albornoz atribuye la irritación de Castro contra "la cantilena de ser españoles 
Séneca, Lucano, Marcial, Prudencio, etc.", a su obstinación "en dar un corte tajante en la historia de España" (Sánchez-Albornoz, 1956, I, 123). Y le recuerda que Séneca profesaba un estoicismo con rasgos hispanos: "escribía en primera persona, refería obscenidades y porquerías y hablaba de sí mismo" (Ibídem, 127), propensiones compartidas por Marcial. Características, me permito añadir, que no provienen de ninguna "esencia" previa de lo hispano, sino de la "existencia" prolongada de grupos étnicos diversos en el mismo ámbito geográfico.

En mis lecturas más placenteras también he encontrado testimonios de la peculiaridad hispana en el Ática romanizada bajo el gobierno de Marco Aurelio. En la segunda mitad del siglo II de nuestra era, el romano Aulo Gelio cuenta en sus Noches áticas que el retórico Antonio Juliano, a quien "se le reconocía como hispano por su acento" (Gelio, 1952, 140), "había traído de Hispania una declamación gritona, una facundia furiosa y disputante". Y como Antonio Juliano tenía escuela pública de elocuencia, concluye Aulo Gelio "¿qué podía esperar de sus ejercicios en una lengua sin voluptuosidad, que lejos de agradar, asustaba a Venus y a las Musas?" (Ibídem, 141). Espero que nuestros amigos mexicanos sean indulgentes con nuestro hablar "golpeado", vicio español de lejano y clásico arraigo.

Los visigodos asumieron la concepción unitaria de Hispania, como reseñó San Isidoro de Sevilla en el primer tercio del siglo VIl y no sólo en su muy citada "De laude Spaniae", que sirve de introducción a su Historia de regibus Gothorum, Vandalorum et Sueborum. En sus menos frecuentadas Etymologiae especifica en latín que Hispania "está situada entre África y Galia, cerrada al septentrión por los montes Pirineos y rodeada del mar por todas partes. Es riquísima por la salubridad de su cielo, por su fecundidad en todo género de frutos y por la abundancia de gemas y metales" (Isidoro, 1951, 347). Luego menciona sus ríos principales -el Betis, el Miño, el Ebro y el Tajo- y las seis provincias establecidas por los romanos: Tarraconense, Cartaginense, Lusitania, Galecia, Bética y, en la región de África, la Tingitania. Y más adelante precisa: "Gades, isla (hoy península) situada al final de la provincia bética y que separa Europa de África; en ella están las columnas de Hércules" (Ibídem, 350).

También los límites de Europa están señalados por San Isidoro de Sevilla en sus Etymologiae: "Europa, tercera parte del orbe, empieza en el río Tanais (el actual Don), desciende al ocaso por el mar Septentrional hasta los fines de Hispania; sus partes oriental y meridional, destacándose del Ponto, están bañadas por el Mare Magnum (el Mediterráneo); y termina en la isla de Gades" (Ibídem, 343-344).

Y en lengua castellana hay múltiples testimonios del sentimiento que prevalecía entre la gente común de pertenecer a un viejo país Ilamado España. En el siglo XII hay cinco menciones expresas a España en el Poema de Mío Cid. Valga de ejemplo la del verso 453: "D'aqueste acorro fablará toda España". En la primera mitad del siglo siguiente, Gonzalo de Berceo cita a España en tres versos de los Milagros de Nuestra Señora y en seis de su Vida de San Millán. El más significativo de estos últimos quizá sea el de la estrofa 371 al quejarse del tributo impuesto por Abderramán: "Yacié toda España en esta servidumbre". Y más adelante, en la estrofa 431, Ilama a San Millán "padrón de los españoles" junto con Santiago. Otro gran escritor medieval, el Arcipreste de Hita menciona, en la primera mitad del siglo XIV, cuatro veces a España en el Libro de Buen Amor, una de ellas en el verso de la estrofa 304: "más orgullo e más brío tienes que toda España".

Antes, en la segunda mitad del XIII, terminó de compilarse por orden de Alfonso X, rey de Castilla y de León, la Primera Crónica General, más conocida por Estoria de España. Ese texto incluye un pasaje de elogios a España inspirados en los encomios que, seis siglos antes, le había dedicado San Isidoro de Sevilla. Y lo que es más importante, en esta Primera Crónica General se lee que, antes de la batalla de Las Navas de Tolosa (1212), Alfonso VIII, rey de Castilla, se apartó "con los de Aragón et portogaleses et gallegos et asturianos"; y les dijo: "Amigos, todos nos somos españoles, et entráronnos los moros la tierra por fuerza et conquiriéronnosla, et en poco estidieron los cristianos que a essa sazón eran que non fueran derraygados et echados della" (Castro, 1973, 77). Al rey de Castilla y al rey de Aragón se les unió pronto el rey de Navarra.

La idea de España como nación no se había olvidado cuando los reyes Isabel y Fernando enlazaron las coronas de Castilla y Aragón con el propósito de restaurar la unidad peninsular. Y se abstuvieron de titularse reyes de España por no ofender al rey de Portugal, quien también se consideraba monarca de una parte de España. Pero, con el establecimiento en 1480 del Consejo Supremo de la Inqui- 
sición, aparato represivo con que la Europa medieval había combatido las herejías, los Reyes Católicos esparcieron las semillas de la decadencia que, desde el subsuelo de las grandezas imperiales, brotaría un siglo y medio después en la nación española.

Durante el reinado de Isabel y Fernando, Antonio de Nebrija compuso la primera Gramática Castellana (1492), y también un Vocabulario latino-español (1492), al que siguió otro español-latino (1495) y un libro de temas arqueológicos: Antigüedades de España (1499). Nada tiene de particular, pues, que Colón Ilamara La Española a la isla que luego se conocería por Santo Domingo. Y que Hernán Cortés, antes de iniciar el asedio de México-Tenochtitlán, solicitara de Carlos I la designación de Nueva España para el país que se proponía conquistar.

En las crónicas de Indias hay frecuentes referencias a los españoles y a España como nación. Valga de muestra la dedicatoria de Francisco López de Gómara en su Historia General de las Indias a "Don Carlos, Emperador de Romanos, Rey de España, Señor de las Indias y Nuevo Mundo". Pocas líneas después menciona a "vuestros españoles", quienes "toman alegremente [el trabajo y el peligro], así en predicar y convertir como en descubrir y conquistar". Y añade: "Nunca nación extendió tanto como la española sus costumbres, su lenguaje y armas, ni caminó tan lejos por mar y tierra, las armas a cuestas" (López de Gómara, $1979,7)$. Alarde tan reprobable para la sensibilidad actual como admirable para los europeos de entonces.

A mediados del siglo XVI, Luis de Camoens, quien también compuso en castellano poemas y fragmentos de algunas comedias, en el canto I de Os Lusíadas llama a los portugueses "una gente fortísima de España". También de Camoens es la expresión: "Portugueses y castellanos, porque españoles lo somos todos", según recoge Claudio SánchezAlbornoz en su España, un enigma histórico (Sánchez-Albornoz, 1956, II, 478, 497).

En pleno apogeo de las letras españolas, las mentes más alertas percibieron el declive imperial. Cervantes plasmó su tristeza risueña en el Quijote. Y Quevedo su desánimo en el soneto que acaba: "Y es más fácil, joh, España!, en muchos modos, / que lo que a todos les quitaste sola / te puedan a ti sola quitar todos". Años antes, Lope de Vega había criticado en La Arcadia un hábito nacional que aún perdura: "¡Ay, dulce y cara España, / madrastra de tus hijos verdaderos! / ¡Y con piedad extraña, / piadosa madre y huésped de extranjeros!"

Quienes reducen la existencia de España a una organización estatal que nace a principios del siglo XIX o finales del XVIII pueden profesar la ideología que prefieran, pero no ignorar los testimonios que, a lo largo de los siglos, han recogido los textos literarios en latín y en román paladino. Incluso en catalán. En el siglo XIX el poeta épico Jacint Verdaguer cantó La batalla de Lepant conducida por el castellano Juan de Austria y por su lugarteniente general el barcelonés Lluís de Requesens. "iNaus d'Espanya, sempre avant!", escribió Verdaguer en su poema. Por cierto que Lluís de Requesens murió en Bruselas siendo el gobernador general de los Países Bajos, tras haber sustituido al Duque de Alba. Y en la segunda mitad del siglo pasado, el escritor José Bergamín, antes de retirarse en sus postrimerías a Hondarribia (en español, Fuenterrabía), había pregonado que San Ignacio, nada castellano, era muy español. También la conducta de Bergamín, errática, temperamental, extremosa, tenía no poco de española.

Aunque cualquier ciudadano de la España actual puede defender por la vía democrática la absoluta independencia de su región -o nación, si lo prefiere-, sus deseos no lo facultan para distorsionar la realidad histórica. Los vecinos de la ciudad de Reus, digamos, pueden abogar por la independencia política y administrativa de su comarca, pero faltarían a la verdad si negaran que ellos son tarraconenses, catalanes, españoles y europeos.

Ya en el siglo XIII los reinos de Castilla y León habían conocido un prerrenacimiento cultural bajo Alfonso $X_{1}$ con razón llamado el Sabio, que se titulaba Rey de las Tres Religiones como hubiera podido declararse de todas las religiones y creencias a las que se acoge la indefensión humana. No es de extrañar que la clerecía de su tiempo lo tildara de blasfemo por haber dicho, según refiere Diego de Colmenares en su Historia de la insigne ciudad de Segovia "en secreto y en público que si asistiera a la creación del mundo, algunas cosas se hicieran diferentes" (Colmenares, 1969, I, 405). Y cuando un monje le pidió en el Alcázar de Segovia que se retractara de sus irreverentes palabras, el Rey le "respondió airado teniendo el aviso por atrevimiento a la majestad real" (Ibídem, 405, 420). Como cabía esperar, la maliciosa ignorancia de su tiempo, que siempre consi- 
deró delito su saber, vio en el rosario de infortunios con que acabó su vida el castigo divino de su impiedad. Más
Alfonsos sabios necesita la España del futuro, cualquiera que sea su organización política en democracia.

\section{BIBLIOGRAFÍA}

Álvarez Junco, José (2001): Mater Dolorosa, Madrid, Taurus.

Camoens, Luis de (1982): Los Lusíadas, Barcelona, Orbis.

Castro, Américo (1973): Sobre el nombre y el quién de los españoles (incluye los ensayos Los españoles: cómo llegaron a serlo y "Español", palabra extranjera: razones y motivos), Madrid, Taurus.

Cervantes, Miguel de (1998): Don Quijote de la Mancha, Barcelona, Instituto Cervantes-Crítica.

Cervantes, Miguel de (1970): Los trabajos de Persiles y Sigismunda, Madrid, Castalia.

Colmenares, Diego de (1969): Historia de la insigne ciudad de Segovia, Segovia, Academia de San Quirce.

Recibido: 9 de diciembre de 2010 Aceptado: 9 de mayo de 2011
García y Bellido, Antonio (1977): Veinticinco estampas de la España antigua, Madrid, Espasa-Calpe.
Gelio, Aulo (1952): Noches áticas, Buenos Aires, Espasa-Calpe.

Gonzalo de Berceo (1976): Obras completas, México, Editorial Porrúa.

Isidoro, San. Arzobispo de Sevilla (1951): Etimologías, Madrid, BAC.

López de Ayala, Pedro (1993): Rimado de palacio, Madrid, Cátedra.

López de Gómara, Francisco (1979): Historia General de las Indias, Caracas, Editorial Ayacucho.

Manrique, Gómez (1984): Regimiento de príncipes, Ocaña, Editorial El Crotalón (facsímil).

Poema del Cid [Cantar de Mío Cid] (1960): Madrid, Espasa-Calpe.

Ruiz, Juan. Arcipreste de Hita (1973): Libro de Buen Amor, Madrid, Gredos.

Sánchez-Albornoz, Claudio (1956): España, un enigma histórico, Buenos Aires, Editorial Sudamericana. 